\title{
Glucocorticoids and Lithium Reciprocally Regulate the Proliferation of Adult Dentate Gyrus-Derived Neural Precursor Cells Through GSK-3 $\beta$ and $\beta$-Catenin/TCF Pathway
}

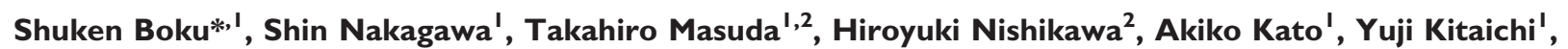 \\ Takeshi Inoue' and Tsukasa Koyama' \\ 'Department of Psychiatry, Hokkaido University Graduate School of Medicine, Sapporo, Japan; ${ }^{2}$ Pharmaceutical Laboratories, Dainippon \\ Sumitomo Pharma Co. Ltd, Osaka, Japan
}

\begin{abstract}
Adult hippocampal neurogenesis is decreased in rodent models for stress-related disorders at least partly through an elevated level of glucocorticoids. On the other hand, the mood stabilizer lithium ( $\mathrm{Li}$ ) commonly used for their treatment increases it. This effect is thought to be one of the therapeutic actions of Li, but the molecular mechanism has been poorly understood. Here we established the culture system of adult rat dentate gyrus-derived neural precursor cells (ADPs) and examined the effects of dexamethasone (DEX), an agonist of glucocorticoids receptor, and Li on ADP proliferation. It is possible for ADP to be a type 2a cell, which corresponds to the second stage in a model of four differentiation stages in adult hippocampal neural precursor cells. DEX decreased ADP proliferation, but Li did not have any effect on it. However, Li recovered ADP proliferation decreased by DEX. The recovery effect of Li was abolished by quercetin, an inhibitor of $\beta$-catenin/TCF pathway. The intranuclear translocation of $\beta$-catenin and expression of cyclin DI are reciprocally regulated by DEX and Li in a way similar to proliferation. In addition, DEX increased the phosphorylation of Tyr ${ }^{216}$, which renders glycogen synthase kinase-3 $\beta$ (GSK-3 $\beta$ ) active on it. These results suggest that GSK-3 $\beta$ and $\beta$-catenin/TCF pathway might be important in the reciprocal effects between DEX and Li on ADP proliferation and are new targets of therapeutic agents for stress-related disorders. Neuropsychopharmacology (2009) 34, 805-8I5; doi:I0.I038/npp.2008.198; published online 12 November 2008
\end{abstract}

Keywords: neurogenesis; stress; hippocampus; dexamethasone; mood stabilizer; Wnt

\section{INTRODUCTION}

It has been well established that neurogenesis occurs in the adult brain of various animal species, including humans (Eriksson et al, 1998; Gould et al, 1997; Gage, 2000). Neurogenesis takes place mainly in two discrete regions of the adult brain: the subventricular zone of the lateral ventricles (Alvarez-Buylla and Garcia-Verdugo, 2002) and the subgranular zone of the dentate gyrus (DG) in the hippocampus (Kempermann et al, 2006). It has been shown that neurogenesis in DG is affected by many factors, including environment, stress, hormones, and drugs. For example, adult neurogenesis in DG is decreased in rodent models for stress-related disorders (Gould et al, 1997; Malberg and Duman, 2003; Pham et al, 2003; Jayatissa et al, 2006). Although it remains unclear how neurogenesis in DG is decreased in these models, some studies have suggested

\footnotetext{
*Correspondence: Dr S Boku, Department of Psychiatry, Hokkaido University Graduate School of Medicine, Kita 15, Nishi 7, Kita-ku, Sapporo, 060-8638 Japan, Tel: + 8 I I| 716 5160, Fax: + 8 I | | 706 508I, E-mail: shuboku@med.hokudai.ac.jp

Received I August 2008; revised 17 September 2008; accepted 4 October 2008
}

that glucocorticoids might be involved in the decrease of adult hippocampal neurogenesis (Gould et al, 1997; Cameron and McKay, 1999; Kim JB et al, 2004). In humans, elevated levels of glucocorticoids constitute one of the causal events in stress-related disorders (de Kloet et al, 2005; Swaab et al, 2005). In contrast, the administration of lithium (Li), which is used for treatment of stress-related disorders, increases adult hippocampal neurogenesis (Chen et al, 2000; Son et al, 2003; Kim JS et al, 2004). These studies suggest that neurogenesis might be involved in the therapeutic action of $\mathrm{Li}$. Therefore, elucidating how glucocorticoids and Li regulate neurogenesis might lead to a further understanding of the pathophysiology of stressrelated disorders and the development of new therapeutic targets. $\mathrm{Li}$ is an inhibitor of glycogen synthase kinase- $3 \beta$ (GSK-3 $\beta$; Klein and Melton, 1996; Stambolic et al, 1996), and GSK-3 $\beta$ is widely known as a key regulator of $\beta$-catenin/TCF pathway (Aberle et al, 1997; Orford et al, 1997).

In this study, we established the culture system of adult rat dentate gyrus-derived neural precursor cells (ADPs) and showed that dexamethasone (DEX), an agonist of glucocorticoid receptor (GR), decreased ADP proliferation and Li recovered it. In addition, we showed that this reciprocal 
effect between DEX and $\mathrm{Li}$ on ADP proliferation was regulated by GSK- $3 \beta$ and the $\beta$-catenin/TCF pathway.

\section{MATERIALS AND METHODS}

\section{Isolation and Culture of ADP}

Adult male Sprague-Dawley rats (8-week old) were deeply anesthetized with sodium pentobarbital and decapitated. The brains were removed and washed with ice-cold phosphate-buffered saline (PBS; $\mathrm{pH}$ 7.4). The coronal sections with a thickness of $1 \mathrm{~mm}$ were cut using a Brain Slicer (Muromachi, Tokyo, Japan) and immersed into dishes containing ice-cold PBS, and the regions containing DG were dissected carefully under a dissecting microscope to exclude all regions containing subependymal tissues (Figure 1a). These tissues were digested with a mixture of papain, dispase II and Dnase I as described earlier (Ray and Gage, 2005). The fraction containing ADP was isolated by Percoll (GE Healthcare, Buckinghamshire, UK) gradient centrifugation and seeded in DMEM: F12 (Sigma, St Louis, $\mathrm{MO}$ ), including $10 \%$ fetal bovine serum (Invitrogen, Carlsbad, CA) and penicillin-streptomycin (Invitrogen) on a noncoating dish, and incubated at $37^{\circ} \mathrm{C}$ in $5 \% \mathrm{CO}_{2}$. After overnight incubation, the medium was changed with a proliferation medium consisting of Neurobasal (Invitrogen), B27 supplement minus vitamin A (Invitrogen), $1 \mathrm{mM}$ L-glutamine (Invitrogen), penicillin-streptomycin, and $20 \mathrm{ng} / \mathrm{ml}$ basic fibroblast growth factor (bFGF; Invitrogen). The cultures were maintained with a proliferation medium at $37^{\circ} \mathrm{C}$ on laminin- (Invitrogen) and ornithin (Sigma)coated dishes and fed with a new medium every 2 or 3 days by replacing $50 \%$ of the medium. When cell confluency reached $80-90 \%$, the cells were passaged by trypsinization a

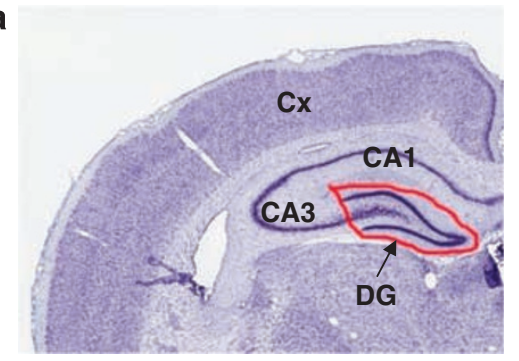

b

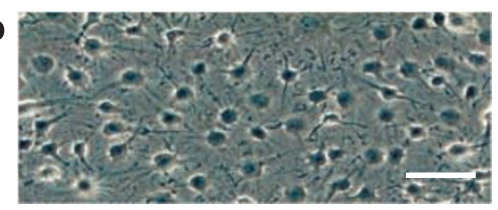

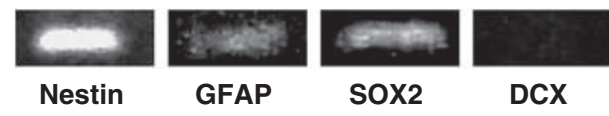

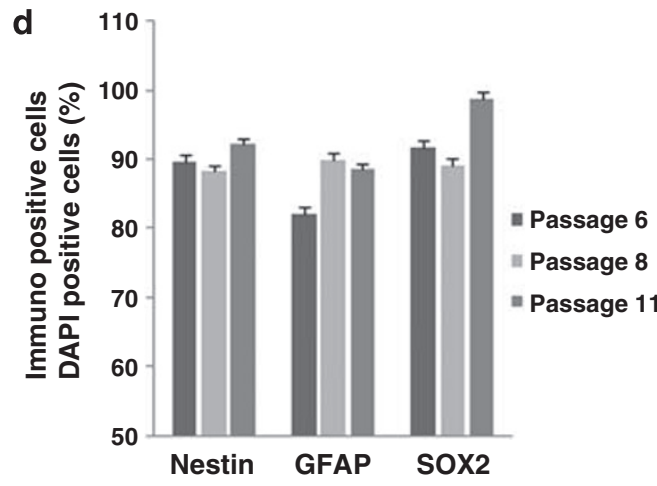

e
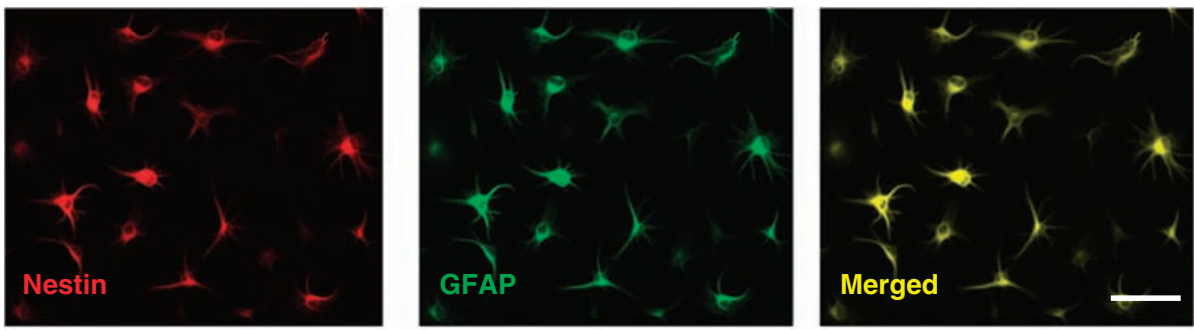

f
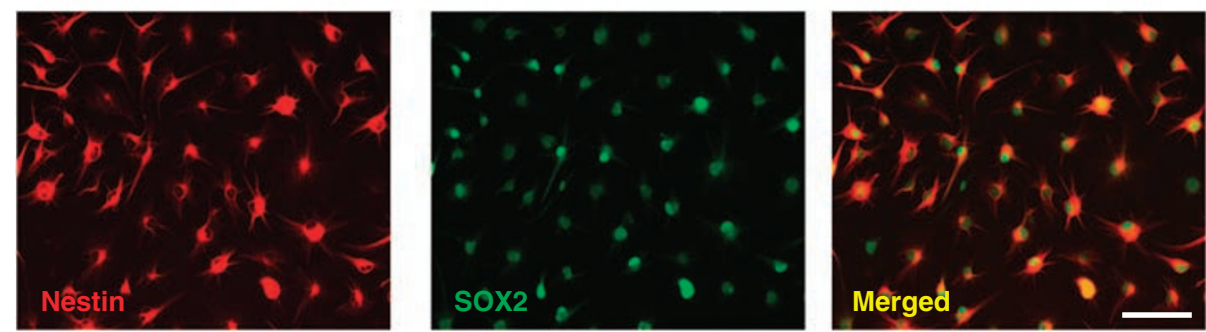

Figure I Isolation and characterization of adult rat dentate gyrus-derived neural precursor cells (ADP). (a) Coronal section through dissected regions. The dentate gyrus (DG) of adult rat was dissected as a red line, and cells were cultured as described in 'Materials and Methods'. Dissection was made carefully to exclude all other regions containing subependymal tissues. (b) The shape of cells. Phase-contrast image was shown at 3 days after passage. Cells grew as a monolayer. Scale bar $=90 \mu \mathrm{m}$. (c) Detection of the genes involved in neural precursor cell and immature neuron with RT-PCR. mRNAs of nestin, GFAP, and SOX2 were detected, but DCX was not. (d) The ratio of immunopositive cells with markers for neural precursor cells in passages 6, 8, and II. Values are shown as the ratio of each marker-positive cell vs 4',6-diamino-2-phenylindole (DAPI)-positive cell. Data are shown as the means \pm SEM. (e, $f$ ) Immunocytochemistry for nestin, glial fibrillary acidic protein (GFAP), and SOX2. (e) Nestin (red), GFAP (green). Scale bar $=120 \mu \mathrm{m}$. (f) Nestin (red), SOX2 (green). Most cells coexpressed nestin, GFAP, and SOX2. Scale bar $=120 \mu \mathrm{m}$. 
and the cell density for seeding was approximately $1 \times 10^{4}$ cells per $\mathrm{cm}^{2}$. The cells were monitored with an IX-70 optical microscope (Olympus, Tokyo, Japan).

\section{Analysis of ADP}

For detecting the expression pattern of markers, $2 \times 10^{4}$ cells per well were seeded in a proliferation medium on laminin- and ornithin-coated Lab-Tek II 8-chamber slides (Nalge Nunc International, Naperville, IL). After overnight incubation, immunocytochemistry was performed as described below. For testing proliferation potency, bromodeoxyuridine (BrdU; Sigma) was added into the medium at $10 \mathrm{nM}$. After $24 \mathrm{~h}$, immunocytochemistry was performed. For testing multipotency, cells were treated in differentiation medium (proliferation medium without bFGF) with $10 \mathrm{ng} / \mathrm{ml}$ brain-derived neurotrophic factor (BDNF; Sigma), $1 \mu \mathrm{M}$ retinoic acid (Invitrogen) $/ 0.5 \%$ fetal bovine serum, or $500 \mathrm{ng} / \mathrm{ml}$ insulin-like growth factor (IGF; Invitrogen). After 7 days, immunocytochemistry was performed.

Cells were fixed with $4 \%$ paraformaldehyde for $15 \mathrm{~min}$. In cases involving detecting the expression pattern of markers and testing for multipotency, permeabilization was performed with PBS containing $0.2 \%$ Triton X-100 for $30 \mathrm{~min}$. In the cases of testing for proliferation potency, permeabilization was performed as follows: Cells were immersed with $50 \%$ formamide in $2 \times$ SSC $(0.3 \mathrm{M} \mathrm{NaCl}, 0.03 \mathrm{M}$ sodium citrate) at $65^{\circ} \mathrm{C}$ for $2 \mathrm{~h}$, incubated in $2 \mathrm{~N} \mathrm{HCl}$ for $30 \mathrm{~min}$ at room temperature, and rinsed in $0.1 \mathrm{M}$ borate buffer for 10 min. Subsequently, the cells were incubated in PBS containing 3\% goat serum (Vector Laboratories, Burlingame, CA) for $20 \mathrm{~min}$ and then with primary antibodies containing $3 \%$ goat serum at $4{ }^{\circ} \mathrm{C}$ overnight. The primary antibodies used were: mouse anti-nestin $(1: 2000 ; \mathrm{BD}$ Biosciences, Franklin Lakes, NJ), rabbit anti-nestin (1:50; Santa Cruz Biotechnology, Santa Cruz, CA), rabbit anti-glial fibrillary acidic protein (GFAP, 1:2000; Dako, Glostrup, Denmark), rabbit anti-SRY (sex-determining region Y)related high mobility group-box gene 2 (SOX2, 1:2000; Chemicon, Temecula, CA), rabbit anti-brain lipid-binding protein (BLBP, 1:300; kindly gifted by Masahiko Watanabe, Hokkaido University Graduate School of Medicine), rabbit anti-Prox1 (1:2000; Chemicon), mouse anti-Tuj1 (1:5000; Covance, Princeton, NJ), and mouse anti-O4 (1:2000; Chemicon). Cells were incubated in PBS containing secondary antibodies for $1 \mathrm{~h}$ at room temperature. The secondary antibodies used were: anti mouse $\mathrm{Cy} 3$ and antirabbit FITC (1:100; Jackson Immuno Research, West Grove, PA). Samples were coverslipped with Vectashield containing 4',6-diamino-2-phenylindole (DAPI; Vector Laboratories). Fluorescent signals were detected using the IX-71 fluorescent microscope system (Olympus).

\section{Cell Counting with Alamar Blue Assay}

Alamar Blue assay is a rapid and simple nonradioactive assay to measure the number of cells. Alamar Blue dye is a fluorogenic redox indicator that is converted from the oxidized form to the reduced form in cells. The reduced form of Alamar Blue dye is highly fluorescent, and the fluorescence in Alamar Blue assay reflects the number of cells (Ahmed et al, 1994; Nakayama et al, 1997). In addition, we confirmed that fluorescence in Alamar Blue assay is surely proportional to the simply counted number of ADPs (data not shown). BrdU-based assays were often used for cell counting, but BrdU-positiveness reflects the duplication of DNA, but not the number of cells. Therefore, we used Alamar Blue assay to estimate the effects of drugs on the number of cells. A total of $1 \times 10^{4}$ cells per well were seeded in $100 \mu \mathrm{l}$ per well of proliferation medium on laminin- and ornithin-coated 96-well plates. After overnight incubation, cells were treated with DEX (Sigma), Li chloride (Wako, Osaka, Japan), SB415286 (Tocris, Ellisville, MO), and/or quercetin (Que; Calbiochem, San Diego, CA) at each concentration. After 3 days, $10 \mu \mathrm{l}$ per well of Alamar Blue solution (Invitrogen) was added into the medium and cells were incubated at $37^{\circ} \mathrm{C}$ for $3 \mathrm{~h}$. The medium $(50 \mu \mathrm{l})$ was dispensed into plates, and the fluorescence intensity of samples was measured by Fluoroscan (Dainippon Sumitomo Pharma, Osaka, Japan) and calculated as described in the manufacturer's manual. Statistical analysis was performed by one-way ANOVA and Dunnet's post hoc test. Significance was defined as $p<0.05$. Data are expressed as the means \pm SEM.

\section{RNA Extraction and Quantitative RT-PCR Analysis}

A total of $1 \times 10^{5}$ cells per well were seeded in a proliferation medium on laminin- and ornithin-coated six-well plates. After overnight incubation, cells were treated with each drug at each concentration. After 3 days, total RNA was extracted from cells with the RNeasy extraction kit (Qiagen, Hilden, Germany). Total RNA was converted to cDNA with the Quantitect Reverse Transcription kit (Qiagen). PCR was performed with the SYBR GreenER qPCR SuperMix for ABI PRISM (Invitrogen) in the ABI PRISM 7000 Sequence Detection System (Applied Biosystems, Foster, CA). The conditions of PCR were: $50^{\circ} \mathrm{C}$ for $2 \mathrm{~min}$ and $95^{\circ} \mathrm{C}$ for $10 \mathrm{~min}$, followed by 40 cycles of $95^{\circ} \mathrm{C}$ for $15 \mathrm{~s}$ and $60^{\circ} \mathrm{C}$ for $1 \mathrm{~min}$. The sequences of forward and reverse primers used were: AGCTGGTCATCAATGGGAAA and ATTTGATGTTAGCGGGATCG for glyceraldehyde 3phosphate dehydrogenase (GAPDH), CTGAGGCCTCTCTT CTTCCA and ATCAGATTCCCCACCCTGA for nestin, TTTCTCCAACCTCCAGATCC and GGTGGCCTTCTGACAC AGAT for GFAP, GAGGAGAGAAAAAGAAAGGAGAGAA and AAGTGCAATTGGGATGAAAAA for SOX2, TAAAAGC CCAGGCCCAAT and TGACTGCTAGAAGTTCCATTTGC for doublecortin (DCX), CTGCTTTGCTCCTGATCTGA and TTC ATAGGATACCTGCAATCTTTG for GR, GATAGAGGCCAA ATTAATCTTTCAA and CCTTCTGCGTCAGCTTAGGT for mineralcorticoid receptor (MR), CAACGCACTTTCTTTC CAGAG and AGGGCTTCAATCTGTTCCTG for cyclin D1, respectively. GAPDH was used as a control. The results were analyzed by using SDS 2.0 software (Applied Biosystems). Statistical analyses were performed by one-way ANOVA and Dunnet's post hoc test. Significance was defined as $p<0.05$. Data are expressed as the means \pm SEM.

\section{Western Blotting}

For preparation of total proteins, $1 \times 10^{5}$ cells per well were seeded in a proliferation medium on laminin- and ornithincoated six-well plates. After overnight incubation, cells were 
treated with each drug at each concentration. After 3 days, lysis of cells and preparation of total proteins were performed with the Mammalian Cell Lysis Kit (Sigma). For preparation of nuclear proteins, $4 \times 10^{5}$ cells per well were seeded in a proliferation medium on laminin- and ornithin-coated $100 \mathrm{~mm}$ dishes. After overnight incubation, cells were treated with each drug at each concentration. After 3 days, lysis of cells and preparation of nuclear proteins were performed with the Nuclear Extract Kit (Active Motif, Carlsbad, CA). Protein concentration was measured by the Protein Assay Kit (Pierce, Rockford, IL), and an equal amount of proteins $(20 \mu \mathrm{l}$ per well) was loaded onto a $10 \%$ SDS gel. The gel was transferred onto a nitrocellulose membrane (GE Healthcare, Milwaukee, WI) and incubated with primary antibodies that were used at the following concentrations: mouse monoclonal anti-cyclin D1 antibody (1:200; Santa Cruz Biotechnology), mouse monoclonal anti- $\beta$-catenin antibody $(1: 200$; Santa Cruz Biotechnology), mouse monoclonal anti-GAPDH antibody $(1: 200$; Santa Cruz Biotechnology), rabbit polyclonal anti-GSK-3 $\beta$ antibody ( $1: 1000$; Cell Signaling, Danvers, MA), rabbit polyclonal anti-pGSK-3 $\beta$ (Ser $\left.{ }^{9}\right)$ antibody (1:1000; Cell Signaling), rabbit polyclonal anti-pGSK-3 $\beta$ ( $\left.\mathrm{Tyr}^{216}\right)$ antibody (1:1000; Biosource, Camarillo, CA). After washing, the membrane was incubated with horseradish peroxidaseconjugated secondary anti-mouse IgG antibody (1:4000; GE Healthcare) or horseradish peroxidase-conjugated secondary anti-rabbit IgG antibody (1:4000; GE Healthcare). Protein expression was detected with the Amersham ECL Plus Western Blotting Detection System (GE Healthcare) and Amersham Hyperfilm ECL (GE Healthcare). The pictures were converted to digital files and the intensity of each band was analyzed with ImageJ (National Institutes of Health, Bethesda, MD). Statistical analyses were performed by one-way ANOVA and Dunnet's post hoc test. Significance was defined as $p<0.05$. Data are expressed as the means \pm SEM.

\section{RESULTS}

\section{Isolation and Culture of ADP}

Tissues from DG of adult Sprague-Dawley rats were dissected carefully to exclude all other regions containing subependymal tissues in which neural stem cells exist (Figure 1a). Cells were dissociated from these tissues as described in Materials and methods, and cultured in a proliferation medium on laminin- and ornithin-coated dishes. In this condition, cells grew at monolayer and did not form any neurospheres. Most cells had a flat and round but slightly elongated shape with short branches, and were phase dark (Figure 1b). It took approximately 4-5 weeks (equal to 5-6 times passages) to get an adequate number of cells for assays. After around 12 times passages, the proliferation potency of cells was decreased, and the shape of cells began to change into smaller and more round ones or more elongated and branched ones. Therefore, we used cells for all assays from P5 to P11.

\section{Characterization of ADP}

First, we saw the mRNA expression of three common neural precursor cell markers, such as nestin, GFAP, and SOX2, and an immature neuron marker, DCX, in the cells with RT-PCR. The mRNA expressions of nestin, GFAP, and SOX2 were detected, but that of DCX was not (Figure 1c). Next, we performed immunocytochemistry for nestin, GFAP, and SOX2. The protein expression of each marker was detected in around $90 \%$ of the cells through different passages (Figure 1d). Moreover, most of the cells were immunolabeled by both nestin and GFAP antibodies at cytoplasm (Figure 1e), and nestin-positive cells were also immunolabeled by SOX2 antibody at the nucleus (Figure 1f). These results indicated that the cells dissociated from adult rat DG expressed nestin, GFAP, and SOX2 in both mRNA and protein, and were uniform in the shape and expression pattern through the passages we examined. In addition, we performed immunocytochemistry for BLBP, another neural precursor cell marker, and Prox1, another immature neuron marker. Protein expression of BLBP was detected as in the cases of nestin, GFAP, and SOX2, but that of Prox1 was not detected (data not shown). Next, we examined whether the nestin-positive cells are dividing or not. Most of the nestin-positive cells were immunolabeled by BrdU antibody (Figure 2A). The ratio of BrdU-positive cells/DAPI-positive cells was about $60-70 \%$ (Figure 2B).

In addition, we examined whether the cells differentiated to neuron or glia with the appropriate medium. The cells were treated with $10 \mathrm{ng} / \mathrm{ml} \mathrm{BDNF}, 1 \mu \mathrm{M}$ retinoic acid $/ 0.5 \%$ fetal bovine serum, or $500 \mathrm{ng} / \mathrm{ml}$ IGF for 7 days. Cells were immunostained by anti-Tuj1 antibody for neuron, antiGFAP antibody for astrocyte, or anti-O4 antibody for oligodendrocyte. Most cells treated with BDNF elongated axon-like branches and expressed Tuj1 (Figure 2C, a). Some cells treated with retinoic acid/fetal bovine serum changed like spread, less-rounded, and expressed GFAP (Figure 2C, b). These cells did not express nestin (data not shown), and their shape was larger and less round than that of untreated cells (Figures 1e and 2C, b), although the untreated cells also expressed GFAP (Figure 1e). A small number of cells treated with IGF formed many of the short dendrites and expressed O4 (Figure 2C, c). These results indicate that the cells dissociated from DG of adult rat brains express three common markers of neural precursor cells and have both proliferation potency and multipotency. Therefore, the cells were identified as neural precursor cells, and we call them ADPs.

\section{DEX and Li have Reciprocal Effects on ADP Proliferation}

Glucocorticoids can bind to both GR and MR (Sousa and Almeida, 2002). To elucidate the expression pattern of these GRs, we examined the mRNA expression of GR and MR in ADP. RT-PCR showed that the mRNA expression of GR was detected, but not that of MR in ADP (Figure 3a). Thus, it is likely to be adequate to use DEX, a specific agonist of GR, for evaluating the effects of glucocorticoids on ADP proliferation. We investigated the effect of DEX on ADP proliferation with Alamar Blue assay. The number of cells was not significantly different between control and $0.5,1,2$, $5,10 \mu \mathrm{M}$ DEX treatment for 1 day or 2 days (data not shown). However, it was significantly decreased with 2, 5, $10 \mu \mathrm{M}$ DEX treatment for 3 days (Figure $3 \mathrm{~b}$ ). The decreased 

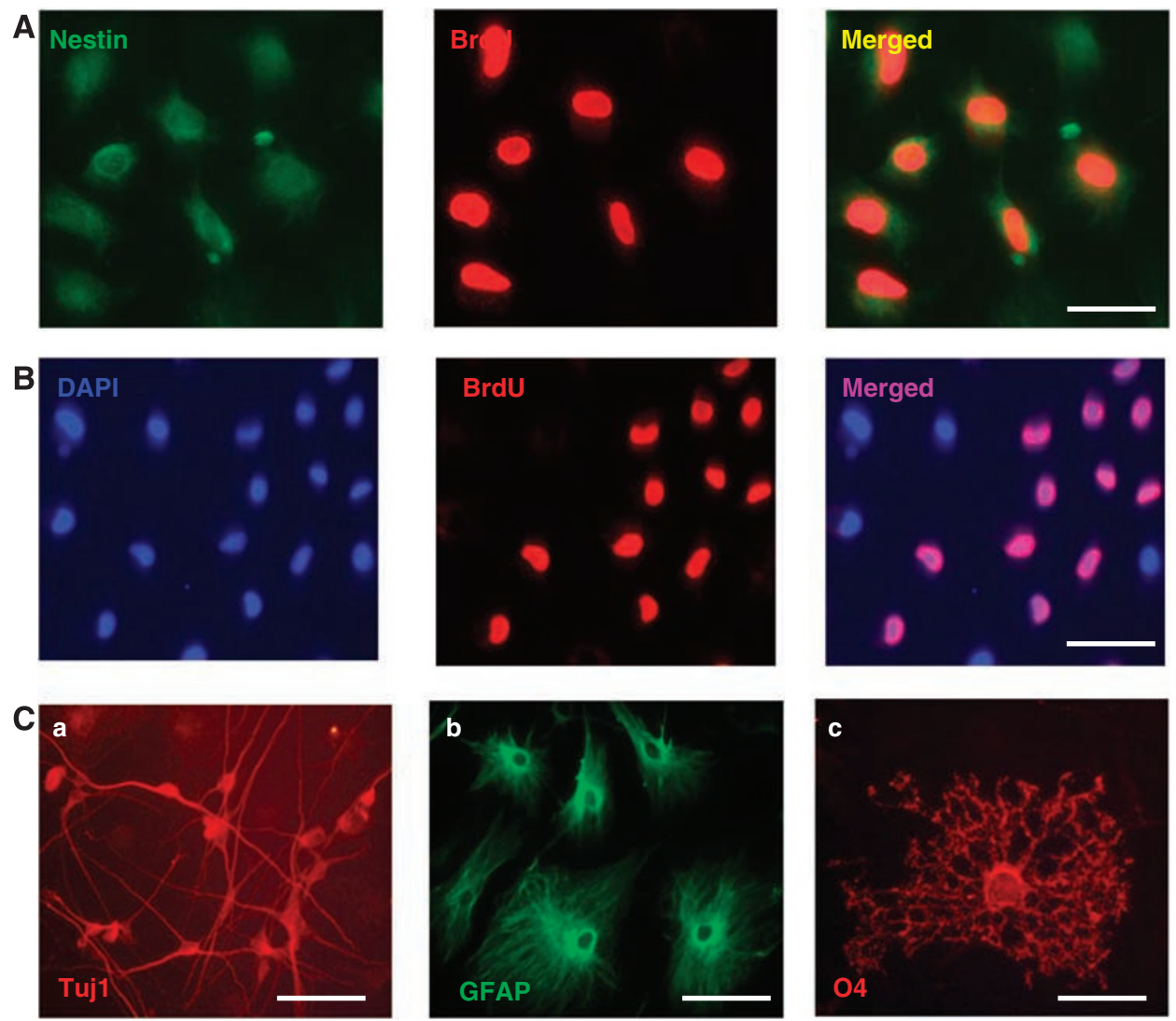

Figure 2 Tests for proliferation potency and multipotency. (A, B) Cells showed proliferation potency. Cells were incubated in I $0 \mathrm{nM}$ bromodeoxyuridine (BrdU) for $24 \mathrm{~h}$ and immunostained with anti-BrdU antibody and anti-nestin antibody. All of the BrdU-positive cells were nestin positive. The ratio of BrdUpositive cells was approximately 60-70\%. Scale bar $=30 \mu \mathrm{m}(\mathrm{A}), 90 \mu \mathrm{m}$ (B), respectively. (C) Cells showed multipotency. Cells were treated with (a) $10 \mathrm{ng} / \mathrm{ml}$ BDNF, (b) | $\mu$ M retinoic acid/0.5\% fetal bovine serum (FBS), and (c) $500 \mathrm{ng} / \mathrm{ml}$ insulin-like growth factor (IGF) for 7 days, respectively. Subsequently, cells were immunostained with anti-Tuj I antibody (a) for neuron, anti-glial fibrillary acidic protein (anti-GFAP) antibody (b) for astrocyte, anti-O4 antibody (c) for oligodendrocyte. Most of the brain-derived neurotrophic factor (BDNF)-treated cells were Tuj I-positive (a). Some of the cells treated with retinoic acid/FBS were GFAP-positive (b). The small number of IGF-treated cells was O4-positive (c). Each of them showed characteristic shape. Scale bar $=90 \mu \mathrm{m}$ (a), $60 \mu \mathrm{m}$ (b), $20 \mu \mathrm{m}$ (c), respectively.

number of cells has three possibilities: decreased proliferation, accelerated differentiation, and apoptosis. To test the possibility of accelerated differentiation, we performed immunostaining with Tuj1, nestin, GFAP, and O4 antibodies, and there were no Tuj 1-positive cells, nestinnegative and GFAP-positive cells, and O4-positive cells (data not shown). To test the possibility of accelerated apoptosis, we performed dUTP nick-end labeling (TUNEL) assay, and any TUNEL-positive cells were not seen (data not shown). In addition, we confirmed that DEX decreased ADP proliferation with BrdU immunocytochemistry (data not shown). Therefore, DEX had no effect on both differentiation and apoptosis in ADP, and we concluded that DEX decreases ADP proliferation. Next, we evaluated the effect of $\mathrm{Li}$ on ADP proliferation. We treated cells with $\mathrm{Li}$ in $0,0.1$, 0.3 , 1 , and $3 \mathrm{mM}$ for 3 days, both in the absence and presence of $5 \mu \mathrm{M} \mathrm{DEX}$, and performed Alamar Blue assay. Li had no effect on ADP proliferation at any concentrations in the absence of DEX (Figure 3c). On the other hand, Li recovered ADP proliferation decreased by DEX to the control level at 1 and $3 \mathrm{mM}$ in the presence of $5 \mu \mathrm{M}$ DEX (Figure 3d). Taken together, these results suggested that DEX and Li had reciprocal effects on ADP proliferation.
Involvement of GSK-3 $\beta$ and $\beta$-Catenin/TCF Pathway in the Reciprocal Effects Between DEX and Li on ADP Proliferation

Li works as an inhibitor of GSK-3 $\beta$ through the direct inhibition of its catalyzed reaction (Klein and Melton, 1996; Stambolic et al, 1996; Davies et al, 2000). However, Li also works as an inhibitor of inositol monophosphatase (Atack et al, 1995). To confirm that the effect of $\mathrm{Li}$ on ADP proliferation is mediated by the direct inhibition of GSK-3 $\beta$, we examined the effects of SB415286, a specific inhibitor of GSK-3 $\beta$ (Coghlan et al, 2000). We found that SB415286 mimicked the effects of Li on ADP proliferation both in the absence of DEX (Figure 4a) and in the presence of $5 \mu \mathrm{M}$ DEX (Figure $4 \mathrm{~b}$ ). Therefore, the direct inhibition of GSK-3 $\beta$ might be involved in the recovery effect of $\mathrm{Li}$ on ADP proliferation.

GSK-3 $\beta$ is widely known as a key regulator of $\beta$-catenin/TCF pathway (Aberle et al, 1997; Orford et al, 1997). Therefore, we investigated the involvement of $\beta$-catenin/TCF pathway in the reciprocal effects between DEX and Li on ADP proliferation with Que, which inhibits $\beta$-catenin/TCF pathway through mainly the inhibition of 
a

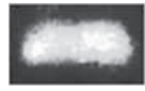

GR

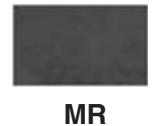

MR

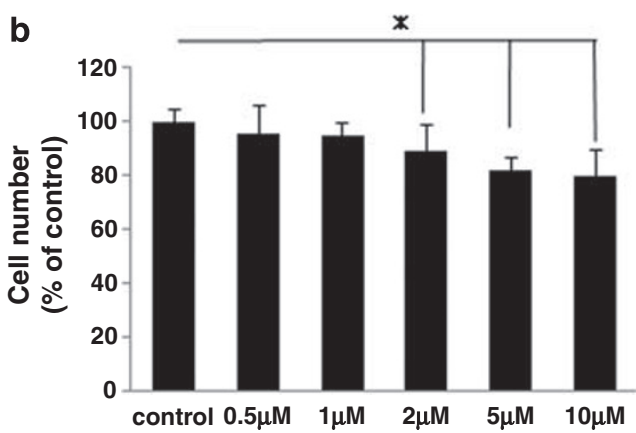

C

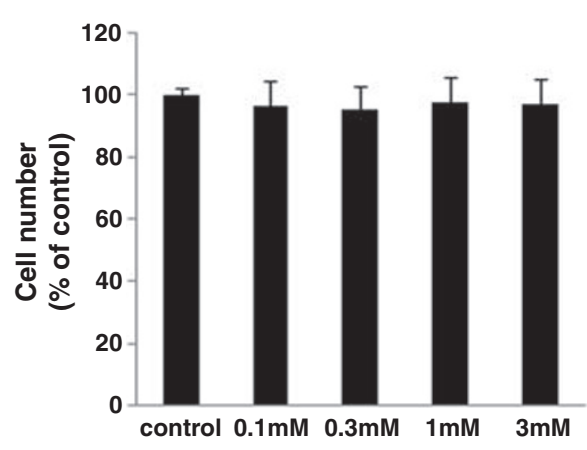

d

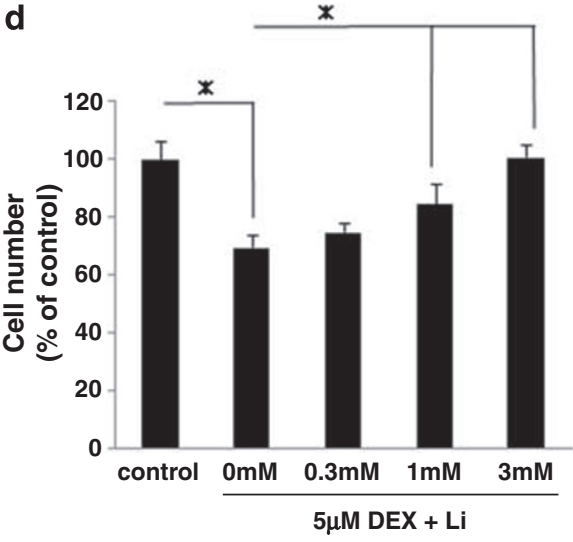

Figure 3 Dexamethasone (DEX) and lithium (Li) have reciprocal effects on adult rat dentate gyrus-derived neural precursor cell (ADP) proliferation. (a) Detection of mRNA of glucocorticoid receptor (GR) and mineralcorticoid receptor (MR) with RT-PCR. mRNA of GR was detected, but mRNA of MR was not detected. (b) DEX decreased ADP proliferation. Alamar Blue assay was performed 3 days after the treatment. Data are shown as the means \pm SEM of four independent cultures. $* 0<0.05$, compared with control. (c) Li had no effect on ADP proliferation in the absence of DEX. Alamar Blue assay was performed 3 days after the treatment. Data are shown as the means \pm SEM of four independent cultures. (d) Li recovered DEX-decreased ADP proliferation. Alamar Blue assay was performed 3 days after the treatment. Data are shown as the means \pm SEM of four independent cultures. $* 2<0.05$, compared with control or $0 \mathrm{mM}$.

nuclear translocation of $\beta$-catenin (Park et al, 2005). Cells were treated with DEX, Li, and Que for 3 days, and Alamar Blue assay was performed. Que had no effect on ADP proliferation decreased by DEX in the absence of $\mathrm{Li}$ (Figure 4c). On the other hand, Que significantly abolished the recovery effect of Li from ADP proliferation decreased by DEX at 10 and $30 \mu \mathrm{M}$ (Figure $4 \mathrm{~d}$ ). These results indicated that $\beta$-catenin/TCF pathway was involved in the reciprocal effects between DEX and Li on ADP proliferation.

\section{Cyclin D1 Expression is Reciprocally Regulated by DEX and Li Through $\beta$-Catenin/TCF Pathway}

Cyclin D1 is a common cell-cycle regulator that controls $\mathrm{G}_{1-}$ $S$ transition through controlling cyclin-dependent kinases, and its expression is regulated by $\beta$-catenin/TCF pathway (Tetsu and McCormick, 1999; Shtutman et al, 1999). We investigated the effect of DEX, Li, and Que for cyclin D1 expression in ADP. Cells were treated with $5 \mu \mathrm{M}$ DEX, $3 \mathrm{mM}$ $\mathrm{Li}$, and/or $30 \mu \mathrm{M}$ Que for 3 days, and quantitative RT-PCR and western blotting were performed. Quantitative analysis showed that DEX significantly decreased cyclin D1 expression in both mRNA (Figure 5a) and protein (Figure $5 \mathrm{~b}$ ) and that $\mathrm{Li}$ recovered it to the control level. However, Que abolished the recovery effect of $\mathrm{Li}$ in both mRNA (Figure 5a) and protein (Figure 5b). Li had no effect on cyclin D1 expression in ADPs in the absence of DEX (data not shown). Taken together, these results indicated that the expression level of cyclin D1 might be reciprocally regulated by DEX and Li through $\beta$-catenin/TCF pathway as in the case with ADP proliferation.

\section{Nuclear Translocation of $\beta$-Catenin is Reciprocally Regulated by DEX and Li}

$\beta$-Catenin is translocated from the cytosol to the nucleus and works as a transcription factor after binding to TCF (Salic et al, 2000). We measured the effects of DEX, Li, and Que on nuclear $\beta$-catenin in ADP. Cells were treated with $5 \mu \mathrm{M} \mathrm{DEX}, 3 \mathrm{mM} \mathrm{Li}$, and/or $30 \mu \mathrm{M}$ Que for 3 days. After that, the nuclear proteins were extracted and western blotting was performed. The protein level of nuclear $\beta$-catenin was decreased with DEX and Li recovered it to the control level (Figure 6a and b). Moreover, Que abolished the recovery effect of Li (Figure $6 a$ and $b$ ). The treatment with Li alone had no effect on the protein level of nuclear $\beta$-catenin (data not shown). These results suggested that the nuclear translocation of $\beta$-catenin might be reciprocally regulated by $\mathrm{DEX}$ and $\mathrm{Li}$, as in the cases of ADP proliferation and cyclin D1 expression.

\section{Effects of DEX on the Phosphorylation States of GSK-3 $\beta$}

Activated GSK- $3 \beta$ phosphorylates $\beta$-catenin and inhibits its nuclear translocation (Aberle et al, 1997; Orford et al, 1997). The activity of GSK-3 $\beta$ is regulated by two 
a

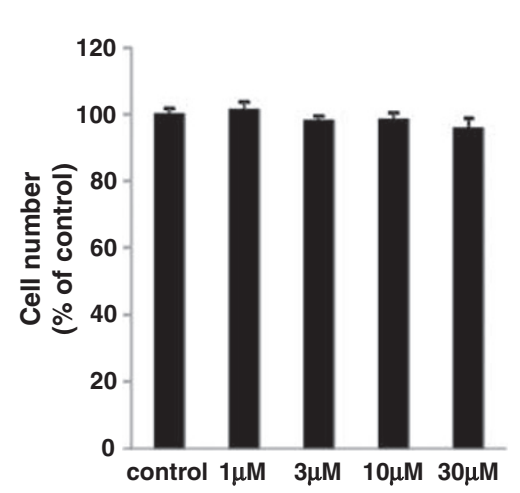

C

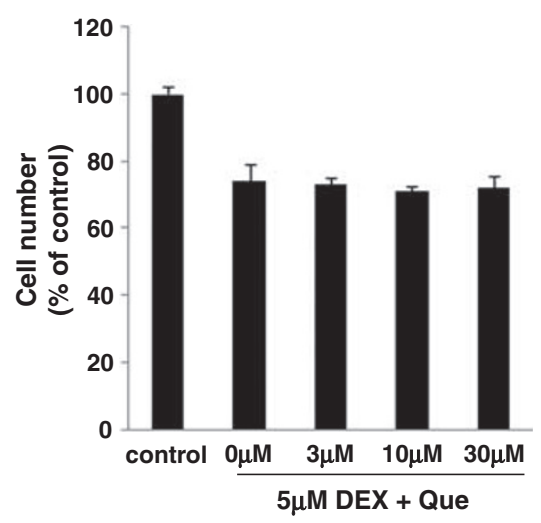

b

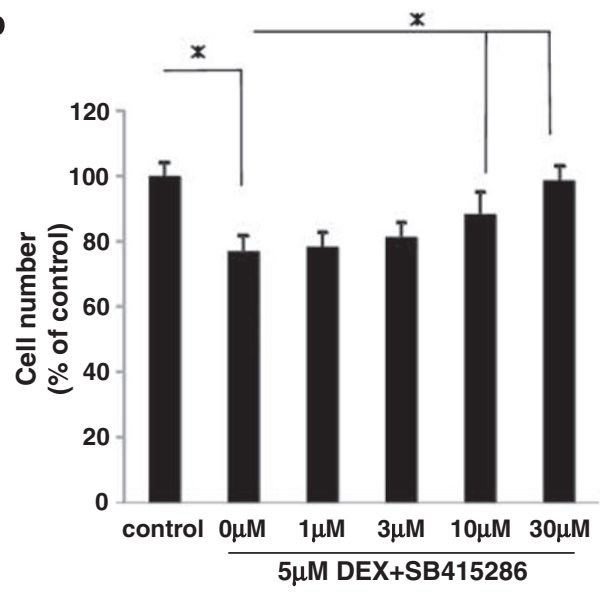

d

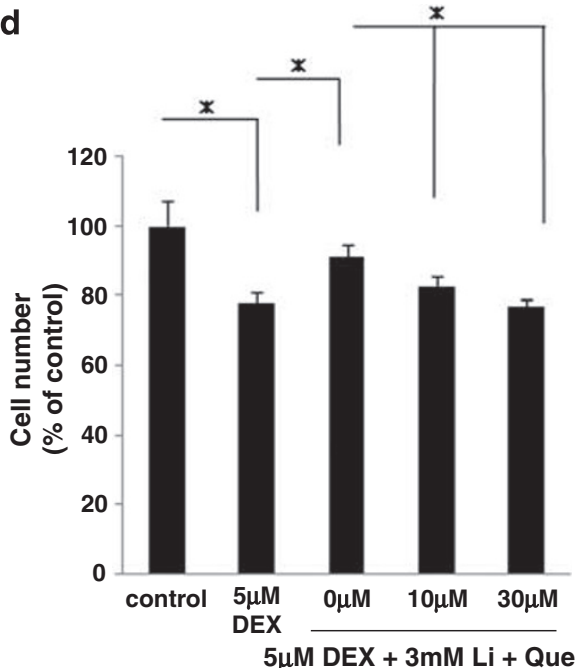

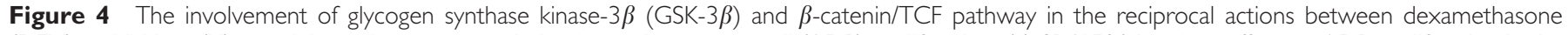
(DEX) and lithium (Li) on adult rat dentate gyrus-derived neural precursor cell (ADP) proliferation. (a) SB4 I 5286 had no effect on ADP proliferation in the absence of DEX. Alamar Blue assay was performed 3 days after the treatment. Data are shown as the means \pm SEM of four independent cultures. (b) SB4 I 5286 recovered DEX-decreased ADP proliferation. Alamar Blue assay was performed 3 days after the treatment. Data are shown as the means \pm SEM of four independent cultures. $p<0.05$, compared with control or $0 \mu \mathrm{M}$. (c) Quercetin (Que) had no effect on ADP proliferation in the absence of Li. Alamar Blue assay was performed 3 days after the treatment. Data are the means \pm SEM of four independent cultures. (d) Que abolished the recovery effect of Li on DEX-decreased ADP proliferation. Alamar Blue assay was performed 3 days after the treatment. Data are shown as the means \pm SEM of four independent cultures. * $p<0.05$, compared with control, $5 \mu \mathrm{M}$ DEX or $0 \mu \mathrm{M}$.

phosphorylated residues; $\operatorname{Ser}^{9}$ to render it inactive (Cross et al, 1995) and $\mathrm{Tyr}^{216}$ to render it active (Hughes et al, 1993). Moreover, Li works as an inhibitor of GSK-3 $\beta$ through the direct inhibition of its catalyzed reaction (Klein and Melton, 1996; Stambolic et al, 1996). Therefore, we investigated whether DEX and Li affect the expression of GSK-3 $\beta$ and the phosphorylation of these residues. Cells were treated with DEX and/or Li for 3 days, and western blotting was performed. $\operatorname{Ser}^{9}$ is well phosphorylated, but $\mathrm{Tyr}^{216}$ is little in the control condition (Figure 7a). DEX increased the phosphorylation of $\mathrm{Tyr}^{216}$ remarkably, but it had no effect on the expression of GSK-3 $\beta$ and the phosphorylation of $\operatorname{Ser}^{9}$ (Figure $7 \mathrm{a}$ and b). Conversely, the treatment of $\mathrm{Li}$ alone or those of DEX and $\mathrm{Li}$ had no effect on all of them (data not shown). Taken together, these results suggested that DEX might decrease ADP proliferation by increasing the phosphorylation of $\operatorname{Tyr}^{216}$ on GSK-3 $\beta$ and that Li might recover ADP proliferation, decreased by DEX through the direct inhibition of its catalyzed reaction, not changing the phosphorylation of $\mathrm{Tyr}^{216}$ on it.

\section{DISCUSSION}

Here we have established the culture system of ADP. ADP is carefully isolated from the dissected DG of adult rats to exclude any subependymal tissues, grows at monolayers in the described condition, and can be passaged 10-11 times with the same character. ADP expresses nestin, GFAP, SOX2, and BLBP, but not DCX and Prox1. In addition, ADP has proliferation potency and multipotency. Some culture systems of neural precursor cells derived from the adult rodent hippocampus have already been reported (Palmer et al, 1997, 1999; Seaberg and van der Kooy, 2002; Bull and Bartlett, 2005; Babu et al, 2007). Our culture system is based on them, but is different in some ways as shown below. Both Seaberg's and Bull's culture systems are derived from mouse 
a

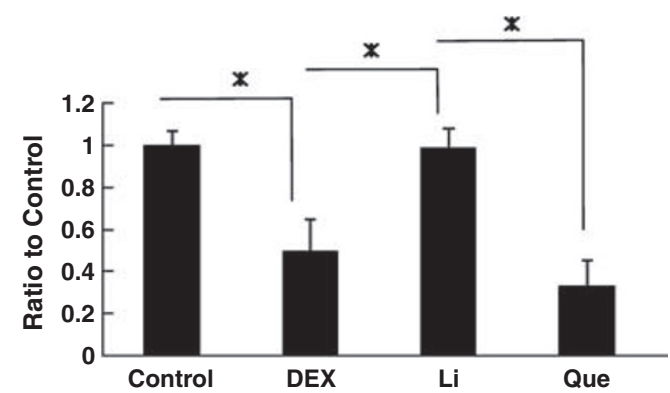

$5 \mu \mathrm{M}$ DEX

$3 \mathrm{mM} \mathrm{Li}$

30uM Que

b

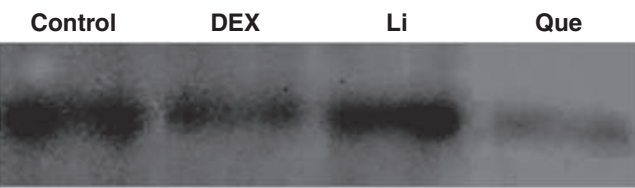

GAPDH

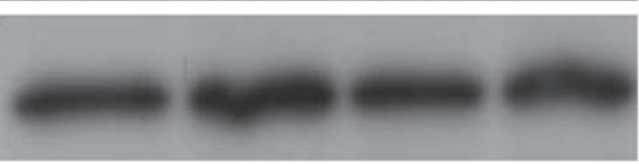

$\boldsymbol{*}$
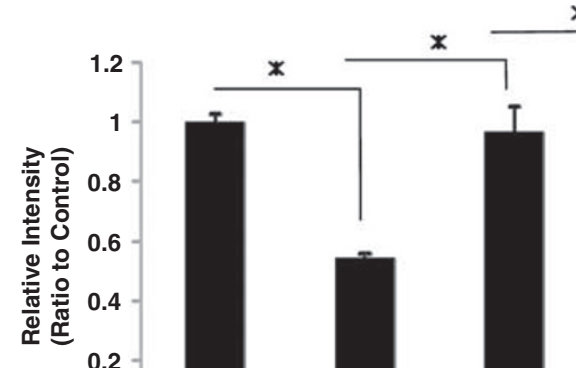

$$
0
$$

Control

DEX

$\begin{array}{ll}5 \mu \mathrm{M} \text { DEX } & - \\ 3 \mathrm{mM} \text { Li } & - \\ 30 \mu \mathrm{M} \text { Que } & -\end{array}$

Figure 5 Cyclin $\mathrm{DI}$ expression is reciprocally regulated by dexamethasone (DEX) and lithium (Li) through the $\beta$-catenin/TCF pathway. (a) DEX decreased mRNA expression of cyclin DI, Li recovered it, and Que abolished the recovery effect of Li. Cells were treated with $5 \mu \mathrm{M}$ DEX, $3 \mathrm{mM} \mathrm{Li}$, and/or $30 \mu \mathrm{M}$ Que. After 3 days, RNA isolation and quantitative RT-PCR were performed. Values are shown as the ratio of cyclin DI mRNA vs glyceraldehyde 3-phosphate dehydrogenase (GAPDH) mRNA. Data are shown as the means \pm SEM of three independent samples. *P $<0.05$, compared with control, DEX, or Li. (b) DEX decreased protein expression of cyclin DI, Li recovered it, and Que abolished the recovery effect of Li. Cells were treated with $5 \mu \mathrm{M}$ DEX, $3 \mathrm{mM} \mathrm{Li}$, and/or $30 \mu \mathrm{M}$ Que. After 3 days, nuclear proteins were prepared, $20 \mu \mathrm{g}$ of them was loaded into each lane, and western blotting was performed. Pictures are shown from a typical experiment that was repeated three times. Data are shown as the means \pm SEM of three independent cultures. $* p<0.05$, compared with control, DEX, or Li.

DG, but their culture conditions differ from ours. Babu's culture system is relatively close to ours, but it is derived from mouse DG and can be passaged many more times than ours. In addition, the properties of adult mouse-derived neural precursor cells may be different from those of adult rat-derived ones (Ray and Gage, 2005). Meanwhile, Palmer's a
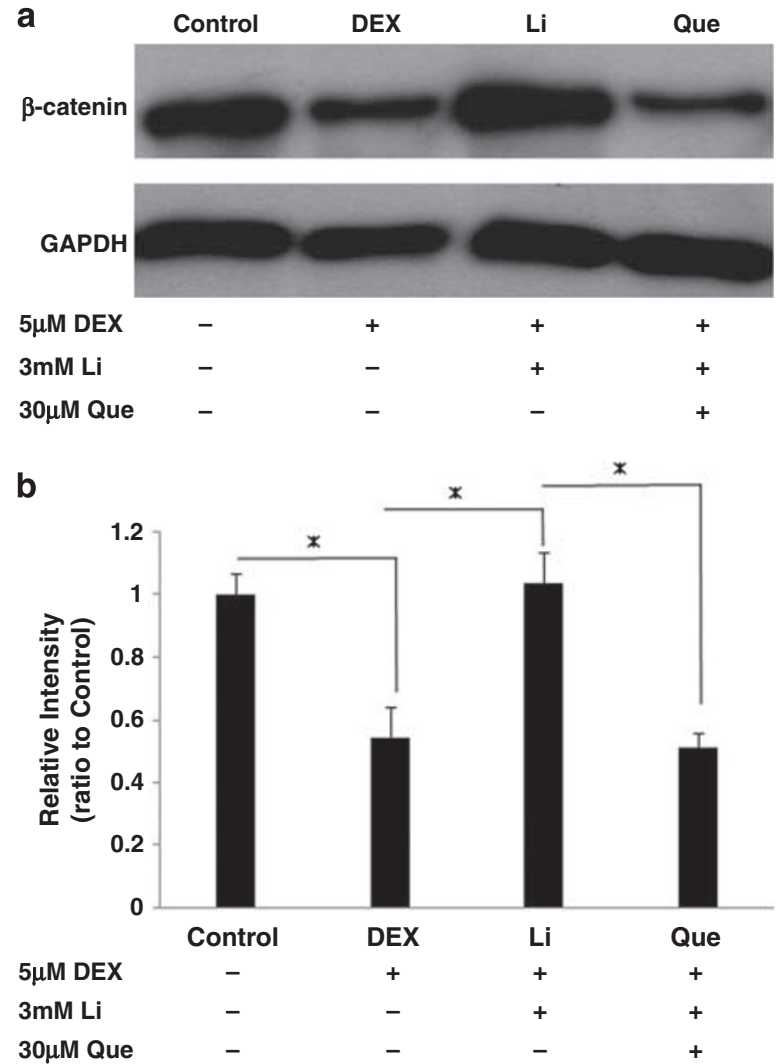

Figure 6 Nuclear translocation of $\beta$-catenin is reciprocally regulated by dexamethasone (DEX) and lithium (Li). (a, b) DEX decreased nuclear $\beta$-catenin, Li recovered it, and Que abolished the recovery effect of Li. Cells were treated with $5 \mu \mathrm{M}$ DEX, $3 \mathrm{mM} \mathrm{Li}$, and/or $30 \mu \mathrm{M}$ Que. After 3 days, nuclear proteins were prepared, $20 \mu \mathrm{g}$ of them was loaded into each lane, and western blotting was performed. In (a), pictures are shown from a typical experiment that was repeated three times. In (b), data are shown as the means \pm SEM of three independent cultures. $* p<0.05$, compared with control, DEX, or Li.

culture system is derived from rat entire hippocampus, but not dissected DG.

Four differentiation stages of precursor cells, including stem and progenitor cells, have been proposed in adult rodent hippocampus in vivo (Seri et al, 2001; Fukuda et al, 2003; Kempermann et al, 2004; Steiner et al, 2006): Cells in the first stage (type-1 cells) express nestin, GFAP, SOX2, and BLBP. Cells in the second stage (type-2a cells) express nestin, SOX2, and BLBP. The expression of GFAP in this stage is vague. Cells in the third stage (type- $2 \mathrm{~b}$ cells) express nestin, DCX, and Prox1, but not GFAP and SOX2 (Kempermann, 2006; Gage et al, 2008). Therefore, the expression pattern of markers on ADPs corresponds to type 1 cell or type 2a cell in vivo. The shape of ADP is different from that of type 1 cell, with an elongated and blanched shape, and is similar to that of type 2 a cell with a flat and round shape (Kempermann et al, 2004). The proliferation potency of ADP is limited; that of type 1 cell is probably unlimited, and that of type $2 \mathrm{a}$ cell is limited (Kempermann et al, 2004). Taken together, ADP could possible be type2a cells. It is poorly understood which stage of neural precursor cells contributes to the reactivity of drugs to neurogenesis. However, a recent study indicated that type 2a-like cells might be a target of fluoxetine, which is an 
a
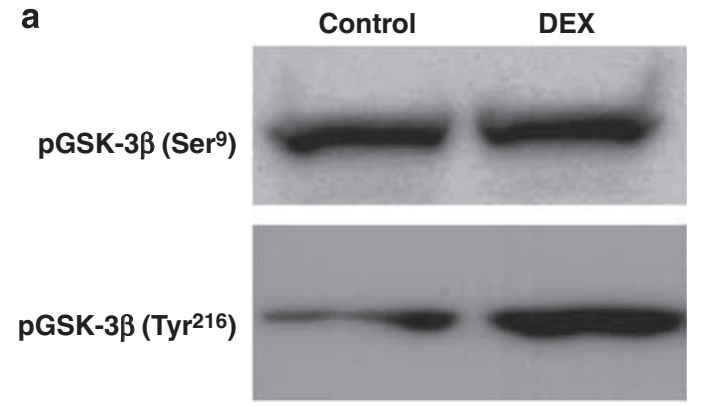

GSK-3 $\beta$

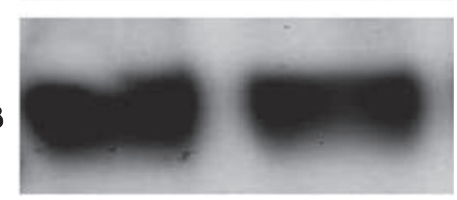

b
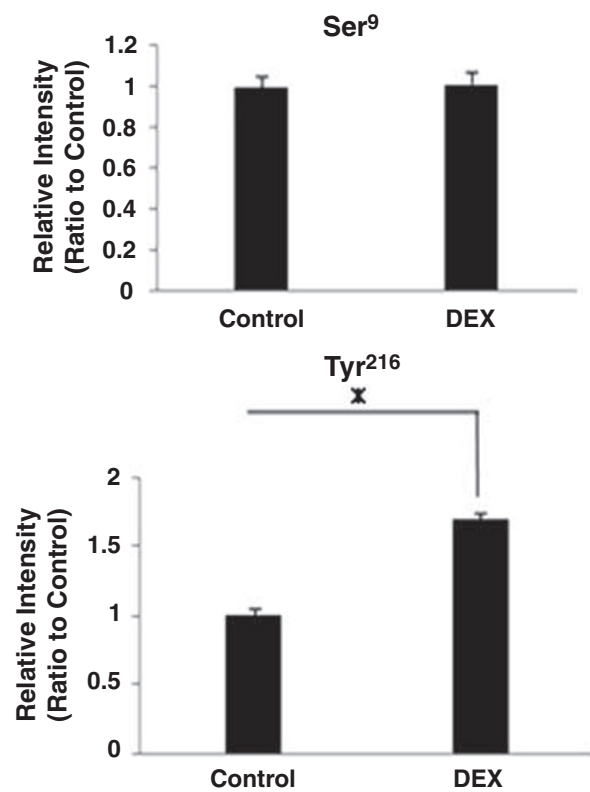

Figure 7 Effects of dexamethasone (DEX) on two phosphorylated

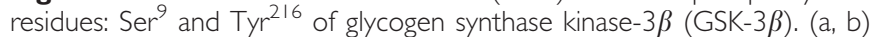
DEX increased the phosphorylation of $\mathrm{Tyr}^{216}$, not but Ser ${ }^{9}$ of GSK-3 $\beta$. Cells were treated with $5 \mu \mathrm{M}$ DEX. After 3 days, $20 \mu \mathrm{g}$ of cell lysates were loaded into each lane and western blotting was performed. In (a), pictures are shown from a typical experiment that was repeated three times. In (b), data are shown as the means \pm SEM of three independent cultures. $* p<0.05$, compared with control.

antidepressant and can increase adult neurogenesis in DG (Encinas et al, 2006). Therefore, it might be beneficial to examine the reactivity of type 2a cells to various drugs and ADPs could be a good model for type2a cells.

Some studies have shown that $\mathrm{Li}$ increases adult neurogenesis in DG of rodents in vivo (Chen et al, 2000; Son et al, 2003; Kim JS et al, 2004). In addition, it has been shown that Li directly increases neural precursor cells derived from the embryo (Kim JS et al, 2004) and adult entire hippocampus (Wexler et al, 2008). However, it remains unclear whether Li directly affects the proliferation of neural precursor cells in DG of adult rodents. To elucidate it, we investigated the effect of $\mathrm{Li}$ on ADP proliferation. Although Li had no effect on ADP proliferation in the absence of DEX, $\mathrm{Li}$ recovered the ADP proliferation decreased by DEX to the control level.
Interestingly, these findings are different from Wexler's results in spite of the closeness of the source of cells. The discrepancy might be due to the difference of the source and character of cells as well as culture condition. We have no answer regarding which culture condition and reactivity to $\mathrm{Li}$ is closer to those of in vivo neural precursor cells in adult DG, and further investigation to answer this question might lead to a further understanding of their character, including the reactivity to various drugs.

It has been shown that the activation of $\beta$-catenin/TCF pathway leads to increasing cyclin D1 expression in tumorderived cell lines (Tetsu and McCormick, 1999; Shtutman et al, 1999). In this study, we found that both cyclin D1 expression and the protein level of nuclear $\beta$-catenin are reciprocally regulated by DEX and $\mathrm{Li}$ as well as ADP proliferation. These results suggest the involvement of $\beta$-catenin/TCF pathway in the reciprocal effects between DEX and Li on ADP proliferation. $\beta$-Catenin/TCF pathway is also well known as the canonical Wnt pathway. It has already been shown that the canonical Wnt pathway regulates the proliferation of embryo-derived neural precursor cells in vitro (Hirsch et al, 2007) and adult hippocampal neurogenesis in vivo (Lie et al, 2005). However, Lie et al showed that the canonical Wnt pathway regulates the proliferation of DCX-positive and elongated cells, which may correspond to type 3 cells and are in the late differentiation stages of neural precursor cells (Kempermann, 2006; Gage et al, 2008). Therefore, our present study is the first report to indicate the involvement of $\beta$-catenin/TCF pathway in the proliferation of hippocampal neural precursor cells in the early differentiation stages.

Moreover, we first clarified the involvement of glucocorticoids in $\beta$-catenin/TCF pathway in adult DG-derived neural precursor cells. There is the possibility that GR directly represses the transcription of cyclin D1 because GR is a transcription factor that can promote or repress the transcription of various genes through direct binding to their promoters (Schoneveld et al, 2004). Our results do not exclude this possibility, and this direct mechanism could regulate ADP proliferation in cooperation with $\beta$-catenin/TCF pathway.

We found that DEX significantly increases the phosphorylation of $\mathrm{Tyr}^{216}$ and has no effect on the phosphorylation of $\operatorname{Ser}^{9}$ on GSK-3 $\beta$. These results suggest that DEX might negatively regulate $\beta$-catenin/TCF pathway through the phosphorylation of $\mathrm{Tyr}^{216}$ on GSK-3 $\beta$. Although it has been shown that glucocorticoids negatively regulate cell proliferation through decreasing the phosphorylation of $\mathrm{Ser}^{9}$ in osteoblasts (Smith et al, 2002), nothing else is known about the effects of glucocorticoids on the phosphorylation states of GSK-3 $\beta$. Therefore, our present study is the first report to indicate the effects of glucocorticoids on the phosphorylation of $\mathrm{Tyr}^{216}$ on GSK-3 $\beta$.

GSK-3 is well known to be encoded by two different genes, GSK-3 $\beta$ and GSK-3 $\alpha$ (Frame and Cohen, 2001; Grimes and Jope, 2001). As most studies of the function of GSK-3 activity in neurogenesis and cell proliferation have focused on the more abundant GSK-3 $\beta$, our present study also focused on GSK-3 $\beta$. However, some studies have highlighted a role for GSK- $3 \alpha$ in neuronal disease (Phiel et al, 2003). In addition, both $\mathrm{Li}$ and SB415286 can inhibit not only GSK-3 $\beta$ but also GSK- $3 \alpha$. Therefore, the limitation of 
our present study is that it does not exclude the involvement of GSK- $3 \alpha$.

We have shown that $\mathrm{DEX}$ and $\mathrm{Li}$ reciprocally regulate ADP proliferation through GSK-3 $\beta$ and $\beta$-catenin/TCF pathway; DEX activates GSK-3 $\beta$ through the phosphorylation of $\mathrm{Tyr}^{216}$; GSK-3 $\beta$ activated by DEX inhibits $\beta$-catenin/TCF pathway, and Li recovers it through inhibiting GSK-3 $\beta$ activated by DEX. However, it remains unclear how DEX increases the phosphorylation of $\mathrm{Tyr}^{216}$ on GSK$3 \beta$. To elucidate it might lead to a further understanding of stress mechanism and the development of new therapeutic targets for psychiatric disorders.

\section{ACKNOWLEDGEMENTS}

This work was supported in part by Grant-in-aid no.18591269 for Scientific Research from the Ministry of Education, Science and Culture, Japan. We thank M Kihara for her expert technical assistance and K Suzuki, T Tanaka, $\mathrm{T}$ Masui, and $\mathrm{H}$ Toda for their helpful critique.

\section{DISCLOSURE/CONFLICTS OF INTEREST}

All the authors declare that they have no conflict of interest.

\section{REFERENCES}

Aberle H, Bauer A, Stappert J, Kispert A, Kemler R (1997). Betacatenin is a target for the ubiquitin-proteasome pathway. EMBO J 16: 3797-3804.

Ahmed SA, Gogal Jr RM, Walsh JE (1994). A new rapid and simple non-radioactive assay to monitor and determine the proliferation of lymphocytes: an alternative to $\left[{ }^{3} \mathrm{H}\right]$ thymidine incorporation assay. J Immunol Methods 170: 211-224.

Alvarez-Buylla A, Garcia-Verdugo JM (2002). Neurogenesis in the adult subventricular zone. J Neurosci 22: 629-634.

Atack JR, Broughton HB, Pollack SJ (1995). Inositol monophosphatase-a putative target for $\mathrm{Li}^{+}$in the treatment of bipolar disorder. Trends Neurosci 18: 343-349.

Babu H, Cheung G, Kettenmann H, Palmer TD, Kempermann G (2007). Enriched monolayer precursor cell cultures from microdissected adult mouse dentate gyrus yield functional granule cell-like neurons. PLOS ONE 2: e388.

Bull ND, Bartlett PF (2005). The adult mouse hippocampal progenitor is neurogenic but not a stem cell. J Neurosci 25: 10815-10821.

Cameron H, McKay RDG (1999). Restoring production of hippocampal neurons in old age. Nat Neurosci 2: 894-897.

Chen G, Rajkowska G, Du F, Seraji-Bozorgzad N, Manji HK (2000). Enhancement of hippocampal neurogenesis by lithium. J Neurochem 75: 1729-1734.

Coghlan MP, Culbert AA, Cross DA, Corcoran SL, Yates JW, Pearce NJ et al (2000). Selective small molecule inhibitors of glycogen synthase kinase-3 modulate glycogen metabolism and gene transcription. Chem Biol 7: 793-803.

Cross DA, Alessi DR, Cohen P, Andjelkovich M, Hemmings BA (1995). Inhibition of glycogen synthase kinase-3 by insulin mediated by protein kinase B. Nature 378: 785-789.

Davies SP, Reddy H, Caivano M, Cohen P (2000). Specificity and mechanism of action of some commonly used protein kinase inhibitors. Biochem J 351: 95-105.

de Kloet ER, Joels M, Holsboer F (2005). Stress and the brain: from adaptation to disease. Nat Rev Neurosci 6: 463-475.
Encinas JM, Vaahtokari A, Enikolopov G (2006). Fluoxetine targets early progenitor cells in the adult brain. Proc Natl Acad Sci USA 103: 8233-8238.

Eriksson PS, Perfilieva E, Bjork-Eriksson T, Alborn AM, Nordborg C, Peterson DA et al (1998). Neurogenesis in the adult human hippocampus. Nat Med 4: 1313-1317.

Frame S, Cohen P (2001). GSK3 takes centre stage more than 20 years after its discovery. Biochem J 359: 1-16.

Fukuda S, Kato F, Tozuka Y, Yamaguchi M, Miyamoto Y, Hisatsune T (2003). Two distinct subpopulation of nestin positive cells in adult mouse dentate gyrus. J Neurosci 23: 9357-9366.

Gage FH (2000). Mammalian neural stem cells. Science 287: 14331438.

Gage FH, Kempermann G, Song H (2008). Adult Neurogenesis. Cold Spring Harbor Laboratory Press: New York.

Gould E, McEwen BS, Tanapat P, Galea LAM, Fuchs E (1997). Neurogenesis in dentate gyrus of adult tree shrew is regulated by psychosocial stress and NMDA receptor activation. J Neurosci 17: 2492-2498.

Grimes CA, Jope RS (2001). The multifaceted roles of glycogen synthase kinase 3beta in cellular signaling. Prog Neurobiol 65: 391-426.

Hirsch C, Campano LM, Wöhrle S, Hecht A (2007). Canonical Wnt signaling transiently stimulates proliferation and enhances neurogenesis in neonatal neural progenitor cultures. Exp Cell Res 313: 572-587.

Hughes K, Nikolakaki E, Plyte SE, Totty NF, Woodgett JR (1993). Modulation of the glycogen synthase kinase- 3 family by tyrosine phosphorylation. EMBO J 12: 803-808.

Jayatissa MN, Bisgaard C, Tingström A, Papp M, Wiborg O (2006). Hippocampal cytogenesis correlates to escitalopram-mediated recovery in chronic mild stress rat model of depression. Neuropsychopharmacology 31: 2395-2404.

Kempermann G (2006). Adult Neurogenesis. Oxford University Press: Oxford.

Kempermann G, Chesler EJ, Lu L, Williams RW, Gage FH (2006). Natural variation and genetic covariance in the adult hippocampal neurogenesis. Proc Natl Acad Sci USA 103: 780-785.

Kempermann G, Jessberger S, Steiner B, Kronenberg G (2004). Milestones of neuronal development in the adult hippocampus. Trends Neurosci 27: 447-452.

Kim JB, Ju JY, Kim JH, Kim TY, Yang BH, Lee YS et al (2004). Dexamethasone inhibits proliferation of adult hippocampal neurogenesis in vivo and in vitro. Brain Res 1027: 1-10.

Kim JS, Chang MY, Yu IT, Kim JH, Lee SH, Lee YS et al (2004). Lithium selectively increases neuronal differentiation of hippocampal neural progenitor cells both in vitro and in vivo. J Neurochem 89: 324-336.

Klein PS, Melton DA (1996). A molecular mechanism for the effect of lithium on development. Proc Natl Acad Sci USA 93: 84558459.

Lie DC, Colamarino SA, Song HJ, Desire L, Mira H, Consiglio A et al (2005). Wnt signaling regulates adult hippocampal neurogenesis. Nature 437: 1370-1375.

Malberg JE, Duman RS (2003). Cell proliferation in adult hippocampus is decreased by inescapable stress: reversal by fluoxetine treatment. Neuropsychopharmacology 28: 1562-1571.

Nakayama GR, Caton MC, Nova MP, Parandoosh Z (1997). Assessment of the Alamar Blue assay for cellular growth and viability in vitro. J Immunol Methods 204: 205-208.

Orford K, Crockett C, Jensen JP, Weissman AM, Byers SW (1997). Serine phosphorylation-regulated ubiquitination and degradation of beta-catenin. J Biol Chem 272: 24735-24738.

Palmer TD, Markakis EA, Willhoite AR, Safar F, Gage FH (1999). Fibroblast growth factor-2 activates a latent neurogenic program in neural stem cells from diverse regions of adult CNS. J Neurosci 19: 8487-8497. 
Palmer TD, Takahashi J, Gage FH (1997). The adult rat hippocampus contains primordial neural stem cells. Mol Cell Neurosci 8: 389-404.

Park CH, Chang JY, Hahm ER, Park S, Kim HK, Yang CH (2005). Quecertin, a potent inhibitor against $\beta$-catenin/TCF signaling in SW480 colon cancer cells. Biochem Biophys Res Commun 328: 227-234.

Pham K, Nacher J, Hof PR, McEwen BS (2003). Repeated restraint stress suppresses neurogenesis and induces biphasic PSA-NCAM expression in the adult rat dentate gyrus. Eur J Neurosci 17: 879-886.

Phiel CJ, Wilson CA, Lee VM, Klein PS (2003). GSK-3alpha regulates production of Alzheimer's disease amyroid-beta peptides. Nature 423: 435-439.

Ray J, Gage FH (2005). Differential properties of adult rat and mouse brain-derived neural stem/progenitor cells. Mol Cell Neurosci 31: 560-573.

Salic A, Lee E, Mayer L, Kirschner MW (2000). Control of betacatenin stability: reconstitution of the cytoplasmic steps of the wnt pathway in Xenopus egg extracts. Mol Cell 5: 523-532.

Schoneveld OJLM, Gaemers I, Lamers WH (2004). Mechanisms of glucocorticoid signaling. Biochim Biophys Acta 1680: 114-128.

Seaberg RM, van der Kooy D (2002). Adult rodent neurogenic regions: the ventricular subependyma contains neural stem cells, but the dentate gyrus contains restricted progenitors. J Neurosci 22: 1784-1793.

Seri B, Garcia-Verdugo JM, McEwen BS, Alvarez-Buylla A (2001). Astrocytes give rise to new neurons in the adult mammalian hippocampus. J Neurosci 21: 7153-7160.
Shtutman M, Zhurinsky J, Simcha I, Albanese C, D’Amico M, Pestell R et al (1999). The cyclin D1 gene is a target of the $\beta$-catenin/LEF-1 pathway. Proc Natl Acad Sci USA 96: $5522-5527$.

Smith E, Coetzee GA, Frenkel B (2002). Glucocorticoids inhibit cell cycle progression in differentiating osteoblasts via glycogen synthase kinase-3 $\beta$. J Biol Chem 277: 18191-18197.

Son H, Yu IT, Hwang SJ, Kim JS, Lee SH, Lee YS et al (2003). Lithium enhances long-term potentiation independently of hippocampal neurogenesis in the rat dentate gyrus. J Neurochem 85: $872-881$.

Sousa N, Almeida OF (2002). Corticosteroids: sculptors of hippocampal formation. Rev Neurosci 13: 59-84.

Stambolic V, Ruel L, Woodgett JR (1996). Lithium inhibits glycogen kinase synthase-3 activity and mimics wingless signaling in intact cells. Curr Biol 6: 1644-1668.

Steiner B, Klempin F, Wang L, Kott M, Kettenmann H, Kempermann $\mathrm{G}$ (2006). Type-2 cells as link between glial and neuronal linage in adult hippocampal neurogenesis. Glia 54: 805-814.

Swaab DF, Bao AM, Lucassen PJ (2005). The stress system in the human brain in depression and neurodegeneration. Aging Res Rev 4: 141-194.

Tetsu O, McCormick F (1999). $\beta$-Catenin regulates expression of cyclin D1 in colon carcinoma cells. Nature 398: 422-426.

Wexler EM, Geschwind DH, Palmer TD (2008). Lithium regulates adult hippocampal progenitor development through canonical Wnt pathway activation. Mol Psychiatry 13: 285-292. 